\title{
A prospective study of physical trauma and multiple sclerosis
}

\author{
William A Sibley, Colin R Bamford, Katherine Clark, Michael S Smith, Jose F Laguna
}

\begin{abstract}
During an eight year period 170 multiple sclerosis (MS) patients and 134 controls without physical impairment were followed closely to record all episodes of physical trauma and to measure their effect on exacerbation rate and progression of MS. There was a total of 1407 instances of trauma, which were sorted into various categories. Overall there was no significant correlation between all-traumas and disease activity. There was, however, a statistically significant negative correlation between traumatic episodes and exacerbations in 95 patients who had exacerbations during the programme, due primarily to less activity of the disease during a three month period following surgical procedures and fractures. Electrical injury had a significant positive association with exacerbation using a three month at-risk period, but there were no other significant positive correlations in any other category of trauma, including minor head injuries; there were no cases of head injury with prolonged unconsciousness. There was no linkage between the frequency of trauma and progression of disability. MS patients had two to three times more trauma than controls.
\end{abstract}

In spite of their potential significance, environmental factors which might influence the course of multiple sclerosis (MS) have seldom been studied in a systematic prospective way. The older medical literature, much of it anecdotal, suggests that many factors may be responsible for new attacks of MS, but most of these studies were retrospective and relied on chart reviews or the memories of patients and their families. Memories can be quite selective: events such as emotional stress or trauma that are followed by an exacerbation are more likely to be recorded than events not followed by worsening of the disease. This problem, and the need for statistical validation of a proposed relationship between trauma and MS, was recognised by McAlpine et al. ${ }^{1}$

For eight years our clinic conducted a prospective study of MS patients in an effort to uncover external factors which might be risk factors. Several years ago we published a report based on the first three years of data on the effects of physical trauma; there was a trend for electrical injuries to be a risk factor, although this did not reach statistical significance. We could not, however, find a positive relationship with other forms of trauma. $^{2}$ Since then, five more years of data have been accumulated, all of it has been reanalysed in greater detail and we now present a report on the completed study.

\section{Methods}

During an eight year period 170 MS patients were followed at monthly intervals. One hundred and four were female (F:M ratio 1·6:1). Their mean age was 43 years. All patients with clinically definite $\mathrm{MS}^{3}$ in the community were eligible to participate if they were able to attend the clinic for periodic examination and willing to cooperate with the rules of the programme. They received no immunosuppressive or other prophylactic treatment during the study, although the more severe clinical exacerbations were commonly treated with 10-14 days of intramuscular corticotropin or oral prednisone. Some patients did not complete the full eight years of the programme due to relocation or late recruitment. Four discontinued to enter a trial of prophylactic immunotherapy and five because of advanced disability (DSS 8 or 9). The mean time in the programme per patient was $5 \cdot 2$ years.

There were 134 controls of similar age and sex without neurological disease followed in a similar manner to permit comparison of the frequency of various events in the two groups. There were 85 females (F:M ratio $1 \cdot 7: 1)$ and the mean age was 40 years. Most of the controls were healthy at entry into the study, although two had rheumatoid arthritis. Many were intermittently disabled for short periods by intercurrent illnesses.

One purpose of the study was to have both patients and controls complete a questionnaire every 30 days, concerned with recording the occurrence of a wide variety of events during the previous month. Included were questions about the occurrence of physical trauma, stressful life events, infections and a variety of other factors. If the questionnaires were not returned, subjects were contacted by telephone and the data recorded by the clinic nurse (KC). Changes in the patients' symptoms were promptly reported to the same person.

Multiple sclerosis patients had a complete neurological examination routinely every three months, including the recording of Kurtzke Functional Scores and Disability 


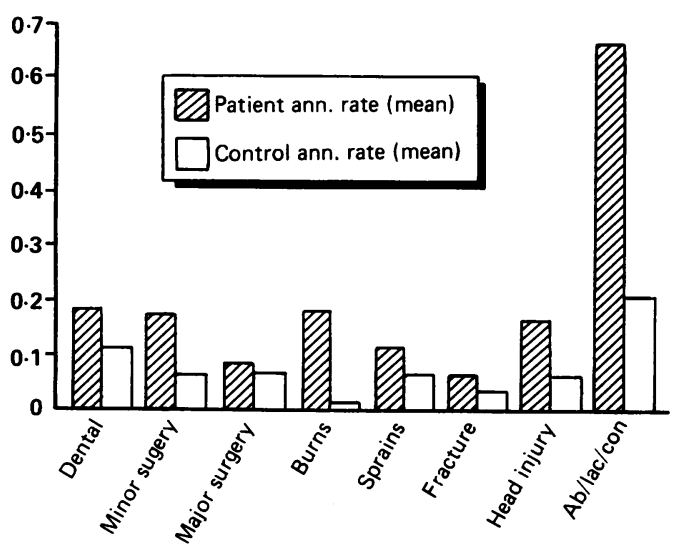

Figure Frequency of various types of trauma in multiple sclerosis patients and controls.

Ab $/$ Lac $/$ Con $=$ abrasions, lacerations and contusions.

Status Scores (DSS). ${ }^{4}$ In addition, patients were examined as soon as possible after the occurrence of any change in symptoms that suggested a possible exacerbation.

We defined an exacerbation as a worsening of old symptoms, or the occurrence of new neurological symptoms, lasting at least 48 hours (in the absence of fever) and associated with an appropriate change in the neurological examination. New symptoms alone were not recorded as an exacerbation. MRI scans were not available during the major portion of the study.

All physical trauma was divided into the following categories: 1) dental procedures (not including cleaning), 2) minor surgery (including suturing of lacerations, removal of skin lesions, uterine dilatation and curettage, endoscopic procedures), 3) major surgery, 4) fractures, 5) sprains (defined as pain around a joint after trauma lasting more than three days, with negative radiographs), 6) burns (with a subcategory of electrical shocks), 7) head injuries (with and without loss of consciousness), and 8) abrasions/ lacerations/contusions ( $\mathrm{ab} / \mathrm{lac} / \mathrm{con}$ ).

The three month (or six month) period following any individual trauma was arbitrarily designated as a period "at risk". Annual exacerbation rates were then calculated during cumulative at risk (AR) periods for each type of trauma, and compared with the annual exacerbation rates for the same group of patients when not at risk (NAR) for any trauma. In the case of simultaneous traumas, the period AR was assigned to the more serious injury. In the event of frequent successive traumas, the period AR terminated at the time of the next trauma: thus AR periods were not allowed to overlap. Because of these factors the cumulative periods AR are not simply a product of the number of incidents times three months (or six months).

\section{Results}

The frequency of most types of trauma was two to three times higher in patients than in controls, as shown in the figure. The discrepancy between the two groups was much higher than this for minor burns. The slightly higher rate of major surgical procedures in the patients was fully accounted for by operations required because of complications of the multiple sclerosis, for example, urological procedures.

The 170 MS patients had a total of 246 acute exacerbations during the course of five years; the distribution of these according to DSS entry score is shown in table 1 . This table also shows the mean progression of these patients during the period of follow up. The data show that exacerbation rates, and progression rates were highest in those with the least disability at entry (DSS scores of five or less).

The 170 MS patients sustained a total of 1407 episodes of physical trauma during the period of the study, which averaged $5 \cdot 2$ years per patient. The number of patients affected by each category of trauma is outlined in table 2 which also lists the time that affected patients were AR for each type of trauma. Included also is the total time NAR for any type of trauma for patients in each row, and the annual exacerbation rates during cumulative AR and NAR periods.

There is no statistically significant difference between the proportion of patients having exacerbations AR and those having exacerbations NAR in any of the rows. The critical value for Chi square in each row is 3.84 $(\mathrm{p}=0.05)$; the Chi square calculation was always done on the actual occurrences, never on the rates. Table 2 is an analysis of the data using a three month AR period. A similar table was constructed using a six month AR period which indicated essentially the same results: nothing approaching a significant difference for

Table 1 Progression of 170 untreated ${ }^{\star}$ MS patients during $5 \cdot 2$ years in a prospective study

\begin{tabular}{|c|c|c|c|c|c|c|c|}
\hline Entry DSS & $P t s$ & $\begin{array}{l}\text { Mean age } \\
\text { years }\end{array}$ & $\begin{array}{l}\text { Mean observation } \\
\text { time (years) }\end{array}$ & Exac & $\begin{array}{l}\text { Mean } \\
\text { exac/yr }\end{array}$ & $\begin{array}{l}\text { Exit DSS } \\
\text { (mean) }\end{array}$ & $\begin{array}{l}\text { Mean increase } \\
\text { DSS/Year }\end{array}$ \\
\hline $\begin{array}{l}0 \\
1 \\
2 \\
3 \\
4 \\
5 \\
6 \\
7 \\
8 \\
9\end{array}$ & $\begin{array}{r}10 \\
22 \\
19 \\
18 \\
14 \\
12 \\
32 \\
28 \\
9 \\
6\end{array}$ & $\begin{array}{l}36 \cdot 8 \\
36 \cdot 6 \\
36 \cdot 8 \\
41 \cdot 3 \\
43 \cdot 6 \\
49 \cdot 0 \\
47 \cdot 8 \\
48 \cdot 4 \\
50 \cdot 8 \\
49 \cdot 8\end{array}$ & $\begin{array}{l}5.48 \\
5.66 \\
4.28 \\
4.59 \\
4.96 \\
5.97 \\
4.97 \\
5.64 \\
6.21 \\
6.23\end{array}$ & $\begin{array}{r}9 \\
63 \\
41 \\
33 \\
21 \\
22 \\
27 \\
27 \\
2 \\
1\end{array}$ & $\begin{array}{l}0.16 \\
0.50 \\
0.50 \\
0.39 \\
0.30 \\
0.30 \\
0 \cdot 16 \\
0 \cdot 17 \\
0.03 \\
0.02\end{array}$ & $\begin{array}{l}0 \cdot 6 \\
2 \cdot 3 \\
3 \cdot 4 \\
4 \cdot 1 \\
5 \cdot 2 \\
5 \cdot 7 \\
6 \cdot 5 \\
7 \cdot 7 \\
8 \cdot 3 \\
9 \cdot 1 .\end{array}$ & $\begin{array}{l}0 \cdot 12 \\
0 \cdot 22 \\
0 \cdot 31 \\
0 \cdot 24 \\
0 \cdot 24 \\
0 \cdot 12 \\
0 \cdot 09 \\
0 \cdot 12 \\
0.05 \\
0.05\end{array}$ \\
\hline$\star \star$ & 170 & & $5 \cdot 2$ & 246 & $0 \cdot 27$ & $5 \cdot 2$ & $0 \cdot 16$ \\
\hline
\end{tabular}

*Untreated except for 10-14 days of ACTH gel or oral prednisone with severe exacerbations.

$\star \star$ The mean entry DSS was $4 \cdot 4$. 
Table 2 Annual exacerbation rates when at-risk ( $A R$ ) for various types of trauma, compared with rates in the same patients when not at-risk (NAR) for any trauma (period $A R=3 M O S$ )

\begin{tabular}{|c|c|c|c|c|c|c|c|c|c|}
\hline Type trauma & Pts & EPIS & Exac/AR & $\begin{array}{l}\text { Time AR } \\
\text { (years) }\end{array}$ & Exac/NAR & $\begin{array}{l}\text { Time } N A R \\
\text { (years) }\end{array}$ & $\begin{array}{l}\text { Exac/year } \\
A R\end{array}$ & $\begin{array}{l}\text { Exac/year } \\
N A R\end{array}$ & Chi square \\
\hline $\begin{array}{l}\text { Dental } \\
\text { Min surg } \\
\text { Maj surg } \\
\text { Burns } \\
\text { Sprains } \\
\text { Fractures } \\
\text { Head inj } \\
\text { Ab/con }\end{array}$ & $\begin{array}{r}78 \\
83 \\
42 \\
71 \\
61 \\
32 \\
67 \\
137\end{array}$ & $\begin{array}{r}162 \\
147 \\
73 \\
157 \\
93 \\
55 \\
140 \\
580\end{array}$ & $\begin{array}{r}11 \\
4 \\
3 \\
13 \\
10 \\
0 \\
9 \\
96\end{array}$ & $\begin{array}{r}32 \cdot 2 \\
29 \cdot 6 \\
16 \cdot 3 \\
33 \cdot 1 \\
19 \cdot 1 \\
11 \cdot 8 \\
28 \cdot 4 \\
114.3\end{array}$ & $\begin{array}{r}75 \\
73 \\
45 \\
83 \\
62 \\
18 \\
75 \\
139\end{array}$ & $\begin{array}{l}311 \cdot 7 \\
324 \cdot 1 \\
153 \cdot 6 \\
245 \cdot 7 \\
199 \cdot 5 \\
116 \cdot 7 \\
251 \cdot 5 \\
479 \cdot 4\end{array}$ & $\begin{array}{l}0.34 \\
0 \cdot 14 \\
0 \cdot 18 \\
0.39 \\
0.52 \\
0 \cdot 0 \\
0 \cdot 32 \\
0.31\end{array}$ & $\begin{array}{l}0 \cdot 24 \\
0 \cdot 23 \\
0 \cdot 29 \\
0 \cdot 34 \\
0 \cdot 31 \\
0 \cdot 15 \\
0 \cdot 30 \\
0 \cdot 29\end{array}$ & $\begin{array}{l}1 \cdot 2 \\
1.0 \\
0.5 \\
0 \cdot 24 \\
2 \cdot 4 \\
1.7 \\
0.03 \\
0.07\end{array}$ \\
\hline Totals & & 1407 & 86 & $284 \cdot 8$ & & & & & \\
\hline
\end{tabular}

any category of trauma. In the six month $A R$ analysis there were 115 exacerbations in 440 years $A R$, and 131 exacerbations in 448 years NAR. Chi square for the three month AR analysis was 0.9 , and for the six month $A R$ analysis $0 \cdot 8$-neither significant.

Since patients with relatively advanced MS are not good indicators of disease activity (table 1), we separately analysed ninety five patients who had one or more exacerbations during the course of the programme. Table 3 is an analysis of exacerbation rates in this group (all traumas), and shows a significantly higher proportion of the exacerbations occurring when NAR for any kind of trauma. (Note that table 3 uses a six month AR period, and that there were 115 exacerbations $A R$ in this analysis: the results are essentially the same using a three month AR period). A detailed analysis of this group of 95 patients is shown in table 4, using the three month AR period: the largest negative correlations between trauma and exacerbation rates are in the categories of surgical trauma and fractures. When the latter two categories were grouped there were 56 patients with 160 episodes of surgery or fracture: among these patients there were seven exacerbations in 33.9 years $A R$, and 97 exacerbations in 217 years NAR, giving annual exacerbation rates of 0.21 and $0.45 \mathrm{AR}$ and NAR, respectively. This difference was significant ( $\mathrm{p}<0.05$; Chi square 4.04). The difference in rates $A R$ and NAR for all other types of trauma grouped was not significant (Chi square $=0.91$ ).

Fifty three patients who had infrequent trauma (mean 0.5 episodes/year) had approximately the same rate of progression of disability as 44 patients experiencing six times more traumatic experiences (mean $3 \cdot 1$ /year). The mean increase in DSS/year was 0.17 in the former group and 0.21 in the latter; the difference was not significant and better explained by a higher entry DSS level in the former group. Additional evidence that disability progression and trauma are not linked derives from the fact that the annual frequency of trauma was approximately the same in 11 patients having improvement in disability during the programme $(2 \cdot 2$ traumas/year) as in 69 patients having no change in disability (mean 1.4 traumas/year), while 90 patients whose DSS increased by one or more points had an average of 1.7 traumas/year. In addition, inspection of the data did not reveal that any particular form of trauma was associated with significantly more rapid progression; long term quantitative analysis of this point is difficult because most patients were subjected to multiple types of trauma during the programme.

Since there is a chance of overlooking possible important special relationships when bulk data are presented, we have examined the question of whether more severe traumas, or perhaps certain types of trauma within the various categories, might be those that produced exacerbation AR.

The period AR following major surgical procedures was a relatively safe time. Forty two patients had 73 such procedures which included the usual assortment in a non-MS population. Thus there were operations on the hip (3), foot (3), knee (2), breast (3), eye (5), ear (2), thyroid (2), gall blader (3), prostate (2), caesarian section (2), laminectomy or rhizotomy (3), hernia repair (4), hysterectomy (10) and miscellaneous other procedures. Some of the operations were related to multiple sclerosis or its complications: there were seven operations involving kidney, bladder, or ureter for stone, one patient had two vertebral artery operations elsewhere, and one had implantation of a dorsal column stimulator, one a penile prosthesis, and two had thalamotomies. One of the three exacerbations $A R$ is patient 5 in table 5. The other two postoperative exacerbations occurred in one patient, two weeks and seven weeks after separate eye surgeries.

All the 140 head injuries were closed head trauma; there were no instances of prolonged unconsciousness, but nine patients had 11 episodes of head trauma associated with definite or probable loss of consciousness for periods varying from seconds to a few minutes. The

Table 3 Effect of physical trauma on exacerbation rates in 95 patients having one or more exacerbations (total exac = 246) ( $A R$ period = 6 months)

\begin{tabular}{lllllllll}
\hline Exac & $P t s$ & Exac/AR & $\begin{array}{l}\text { Time AR } \\
\text { (years) }\end{array}$ & Exac/NAR & $\begin{array}{l}\text { Time NAR } \\
\text { (years) }\end{array}$ & $\begin{array}{l}\text { Exac rate } \\
\text { AR }\end{array}$ & $\begin{array}{l}\text { Exac rate } \\
\text { NAR }\end{array}$ & Chi square \\
\hline$=,>1$ & 95 & 115 & 274 & 131 & 231 & 0.41 & 0.57 & $4.86 \mathrm{p}<0.05$ \\
$=,>2$ & 62 & 105 & 202 & 108 & 145 & 0.52 & 0.74 & $6.96 \mathrm{p}<0.01$ \\
\hline
\end{tabular}

$\star A R-a t$ risk after any type of trauma. 
Table 4 The effects of trauma on exacerbation rates in $95 M S$ patients with one or more exacerbations (period $A R=3 M O$ with $S$ )

\begin{tabular}{|c|c|c|c|c|c|c|c|c|c|}
\hline Type trauma & Pts & $E P I S$ & $E x a c / A R$ & $\begin{array}{l}\text { Time } A R \\
\text { (years) }\end{array}$ & Exac/NAR & $\begin{array}{l}\text { Time NAR } \\
\text { (years) }\end{array}$ & $\begin{array}{l}\text { Exac/year } \\
A R\end{array}$ & $\begin{array}{l}\text { Exac/year } \\
N A R\end{array}$ & Chi square \\
\hline $\begin{array}{l}\text { Dental } \\
\text { Min surg } \\
\text { Maj surg } \\
\text { Burns } \\
\text { Sprain } \\
\text { Fracture } \\
\text { Head inj } \\
\text { Ab/con }\end{array}$ & $\begin{array}{l}40 \\
44 \\
25 \\
47 \\
38 \\
15 \\
44 \\
81\end{array}$ & $\begin{array}{r}94 \\
81 \\
52 \\
98 \\
60 \\
27 \\
89 \\
375\end{array}$ & $\begin{array}{r}11 \\
4 \\
3 \\
13 \\
10 \\
0 \\
9 \\
36\end{array}$ & $\begin{array}{r}18 \cdot 8 \\
16 \cdot 3 \\
11 \cdot 6 \\
21 \cdot 0 \\
12 \cdot 0 \\
6 \cdot 0 \\
17 \cdot 6 \\
74 \cdot 1\end{array}$ & $\begin{array}{r}74 \\
73 \\
46 \\
83 \\
61 \\
19 \\
80 \\
139\end{array}$ & $\begin{array}{r}146.0 \\
174.4 \\
90 \cdot 0 \\
164.5 \\
125 \cdot 0 \\
48.9 \\
168 \cdot 3 \\
282.3\end{array}$ & $\begin{array}{l}0.59 \\
0 \cdot 18 \\
0.26 \\
0.52 \\
0.75 \\
0.00 \\
0.51 \\
0.47\end{array}$ & $\begin{array}{l}0.51 \\
0.41 \\
0.51 \\
0.50 \\
0.49 \\
0.39 \\
0.48 \\
0.49\end{array}$ & $\begin{array}{l}0 \cdot 2 \\
2 \cdot 1 \\
1 \cdot 35 \\
0 \cdot 02 \\
1 \cdot 47 \\
2 \cdot 34 \\
0.04 \\
0.09\end{array}$ \\
\hline
\end{tabular}

Table 5 Electrical injury and MS exacerbations

\begin{tabular}{llllllllll}
\hline Period AR & Pts & Epis & Exac-AR & $\begin{array}{l}\text { Time AR } \\
\text { (years) }\end{array}$ & Exac-NAR & $\begin{array}{l}\text { Time NAR } \\
\text { (years) }\end{array}$ & $\begin{array}{l}\text { Exac/yr/AR } \\
\text { (mean) }\end{array}$ & $\begin{array}{l}\text { Exac/yr/NAR } \\
\text { (mean) }\end{array}$ & Chisquare \\
\hline 3 months & 17 & 19 & 4 & 3.9 & 20 & 66.7 & 1.02 & 0.3 & $5.74 \mathrm{p}<0.02$ \\
6 months & 17 & 19 & 5 & 6.5 & 18 & 50.7 & 0.76 & 0.35 & $2.44 \mathrm{~ns}$ \\
\hline
\end{tabular}

time AR for these 11 episodes was $2 \cdot 15$ years and two exacerbations occurred $A R$ giving an annual exacerbation rate AR of 0.92 for this small group. The same nine patients had 10 exacerbations during 31.9 years NAR during the study (rate $=0.32$ ). The difference is not significant (Chi square $=2 \cdot 07$ ). (One of the AR exacerbations was questionable: it occurred in a moderately disabled patient on the same day as the head trauma, from a fall. Since the exacerbation included increased weakness of the legs and ataxia, the new neurological symptoms may have preceded, and caused, the head trauma.)

Electrical injuries are included as instances of burns in tables 2 and 4, but in fact none of the injuries were of sufficient current strength to produce significant burns. Electric shock was reported in 19 instances in 17 patients. There was an exacerbation four times during a three month AR period (five exacerbations during a six month AR period). Two of the four patients were handling a 110 volt alternating current electrical appliance (three of five for the six month AR period). One other patient having an exacerbation $A R$ reported an electric shock from a low voltage transcutaneous stimulator, and another reported an electric shock while attempting to repair a television set. In the case of the alternating current shocks, the current pathway was arm-to-arm or arm-to-leg. The current pathway in the case of the television repairman could not be determined-he experienced ataxia and facial pain five days after the shock; it is not known if his head was grounded at the time of the shock, though this seems unlikely. The history of the patient having arm-to-arm current flow was presented in a previous report. ${ }^{2}$

Statistical analysis suggests that electrical shock is a risk factor (table 5); the distributions of exacerbations AR and NAR reaches significance for the three month AR analysis. The interval between the shock and exacerbation was one, five, $60,60,65$ days, and five months in the various cases cited.

Exacerbation occurred during a three month AR period in 10 of 89 instances of sprain. Two of 24 cases of lumbar back strain were followed by exacerbation after 30 and 44 days. Three of 11 instances of wrist/hand sprain were followed by exacerbation AR, two of 33 ankle sprains, one of two elbow sprains, and two of five neck sprains. Exacerbation after neck sprain occurred 20 days after trauma (unilateral retrobulbar neuritis) and 52 days later (right arm weakness and numbness).

Table 6 describes the 15 exacerbations occurring within 14 days after a traumatic episode. The exacerbation may be responsible for the trauma in cases 1,2 , and 6 . Cases $4,7,8$, 11 and 13 in this table were associations with the minor lacerations and contusions which commonly occurred in our patients.

Table 6 Exacerbations occurring two weeks or less after trauma

\begin{tabular}{llll}
\hline & Form of trauma & $\begin{array}{c}\text { Interval } \\
\text { (days) }\end{array}$ & Description of exacerbation \\
\hline 1) & Head injury from fall & 0 & Paraparesis, Horner's syndrome \\
2) & Laceration hand, fall & 0 & Vertigo, numb face, dysarthria \\
3) & Electric shock, hands & 1 & Numbness left neck and breast \\
4) & Contusion right finger & 2 & Left hemiparesis \\
5) & Left knee surgery & 2 & Left leg weaknes \\
$6)$ & Sprain left ankle & 2 & Paresthesias, weakness both legs \\
7 () & Laceration finger, razor & 3 & Paraparesis \\
8) & Laceration palm & 4 & Ataxia, pain right eye \\
9) & Electric shock, TV repair & 5 & Ataxia, facial pain \\
10) & Thorn in foot & 9 & Anarthria, later dysarthria, numbness hands \\
11) & Minor burns, hands & 11 & Diplopia \\
12) & Root canal, right & 12 & Right facial numbness, bilateral external rectus muscle \\
13) & Laceration leg, car door & 12 & palsies \\
14) & Incision and drainage right peritonsillar abscess & 12 & Acute urinary retention \\
15) & Surgery, retina & 14 & Acute paraparesis \\
\hline
\end{tabular}




\section{Discussion}

The possibility that trauma might influence the course of MS has been proposed by a number of authors, including McAlpine et al, ${ }^{1}$ Miller, ${ }^{5}$ and Millar. ${ }^{6}$ The literature dealing with this issue has been reviewed in detail by others. ${ }^{27}$ McAlpine and Miller suggested that peripheral trauma can result in exacerbation, postulating a change in vascular responses in the CNS after such trauma. A deficiency in all reports of a positive association has been failure to include all cases of trauma, a procedure necessary to establish trauma as a risk factor in a disease so notoriously variable as MS; also most reports have been retrospective, which introduces a potential problem of selective memory for positive associations.

The current study is the only long-term prospective study of the problem. It is also the only study which has examined the issue of trauma as a possible cause of exacerbation or increased rate of progression in patients with established MS and recorded all instances of trauma, and compared exacerbation rates in post-traumatic periods to those occurring in the same patients when not at risk. Certainly the major conclusion from the study is that peripheral trauma is not a significant risk factor, overall, or for any of the major subcategories of trauma. An exception is the subcategory of electrical injury.

McAlpine et al $^{18}$ and Miller and Schapira ${ }^{9}$ each reported single patients with worsening after electrical injury: these patients developed numbness of the injured limb three and six days following a shock, very similar to the history of one of our patients (case 3, table 6). Even our finding of a statistically significant relationship, however, should be viewed cautiously, since the numbers are small and few other cases have been reported. Also the significance of the association in our series was increased by including one instance of exacerbation when AR for an electric shock from a transcutaneous stimulator; these battery operated devices emit currents of very low strength, less than 100 milliamps, ${ }^{1011}$ and such low voltage devices are not usually associated with any biological injury. ${ }^{12}$ Thus the appropriatenesss of including this patient could be questioned.

In this report we have arbitrarily used both a three and a six month period AR. The six month period was used in a previous report; we repeated the analysis using a three month risk period. The results of the two analyses were not significantly different, except in the case of electrical injury. We have not analysed the data using shorter AR periods, although our finding that 15 of 86 exacerbations AR occurred during the first two weeks of the three month AR period is very close to what would be expected by chance.

Von Hoesslin was the first to propose a relationship between the site of injury and the level of the new MS lesion in the nervous system; ${ }^{12}$ subsequently McAlpine et al and Miller have cited selected cases in which this relationship has been striking, and mentioned this as confirmatory evidence of the reality of traumatic precipitation of new attacks.
McAlpine found, for example, in a retrospective study, that in 22 of 36 patients with dental extraction there was a correlation between injury site and the level of the initial MS lesion. ${ }^{1}$ In the cases described in this report, we too saw examples of striking injury-site/lesion correlation. This was true in cases $3,5,12$, and 14 (table 6). One was a patient with arm-to-arm electric shock, and one a patient who developed weakness of the same leg two days after knee surgery. The other two cases involved oral surgery. Dental procedures were not, however, a risk factor (tables 2 and 4 ). In the cases of 10 other patients having exacerbations 15-90 days after dental procedures the exacerbations were probably due to spinal cord or cerebral lesions in seven, and in only three of these was brain stem localisation likely. Thus it would seem to us that injury site/lesion level correlation, as well as the occurrence of new attacks shortly after traumatic events is most likely to be fortuitous. Certainly the frequency of new MS lesions and the frequency of traumatic events allows ample opportunity for such chance associations.

Poser $^{7}$ and Gonsette et $a^{13}$ suggest that increased vascular permeability is a necessary event in the development of a new MS lesion; as evidence they cite the demyelination seen in some brains of MS patients about the path of trocars inserted during the course of thalamotomies, and Kelly's mention of frequent exacerbation after these procedures. ${ }^{14}$ Poser cites selected case reports showing a close temporal relationship between trauma and exacerbation, but does not present data about unassociated traumas. He proposes that even minor head and neck injuries may cause exacerbation based on these anecdotal reports. All the head injuries in our study were mild closed injuries; while there was brief loss of consciousness in a number of patients, none had prolonged loss of consciousness. Our data, however, include an adequate sample of such minor head injuries and fail to implicate these as a risk factor.

Without precise knowledge about the pathogenesis of the MS lesions, it is difficult to be sure if the increased vascular permeability seen in many MS lesions by enhanced scans is secondary to the inflammation associated with these lesions, or if it is essential to their development. Two of our patients had thalamotomies; both had rapidly progressive severe disease before, as well as after, making it impossible to draw conclusions about the effect of the trauma of the procedures. Thus our data do not contribute any new information about the effect of severe or penetrating head injuries; in such cases it would be very difficult to distinguish the effects of direct trauma from the effects of MS.

The greater frequency of trauma in our MS patients than in controls is notable. Unlike McAlpine et al, we elected to record all instances of trauma, not just those judged to be unrelated to impairment; in many instances such judgements would have been difficult or impossible. Also if the hypothesis that trauma is capable of worsening the MS process is 
correct, the distinction should be irrelevant.

The statistically significant negative correlation between trauma and exacerbation rate was due mostly to a low frequency of worsening after surgical procedures and fractures. There was no logical reason to group these categories together, although arguably these may have been the most severe traumas sustained by our patients. We grouped them primarily to show the principal source of the negative association. Ridley and Schapira in a retrospective analysis of major surgical procedures also found the post operative period to be relatively safe: in 57 operations there were no acute exacerbations in the first postoperative month. ${ }^{15}$

If trauma is not a major risk factor in MS, what external circumstances did correlate with worsening in our patients during this prospective study? We have previously reported that clinical viral infections were the most impressive environmental influence; the exacerbation rate during cumulative periods $\mathrm{AR}$ for such infections was 0.64 per annum, compared with a rate of 0.23 during periods NAR (Chi square $=56.3 ; \mathrm{p}<0.0001) .{ }^{16}$ Another report from our clinic emphasised that stressful life events were a much weaker risk factor with the exacerbation rates AR and NAR being 0.36 and 0.26 respectively $(\mathrm{Chi}$ square $=4 \cdot 8$; p < 0.05); it seemed likely, however, that the apparent significance of stressful life events might be spurious due to patient bias during periods when concurrent reporting of stress and exacerbation was possible. ${ }^{17}$
This work was supported by grant 1048-C-13 from the National Multiple Sclerosis Society, New York.

1 McAlpine D, Compston N. Some aspects of the natural history of disseminated sclerosis. QJ Med 1952;21 135-67.

2 Bamford CR, Sibley WA, Thies C, Laguna JF, Smith MS Clark K. Trauma as an etiologic and aggravating factor in multiple sclerosis. Neurology 1981;31:1229-34.

3 Schumacher GA, Beebe G, Kibler RF, et al. Problems of experimental trials of therapy in multiple sclerosis: report by the panel on evaluation of experimental trials of therapy in multiple sclerosis. Ann NY Acad Sci 1965;122:552-68.

4 Kurtzke JF. On the evaluation of disability in multiple sclerosis. Neurology 1961;11:686-94.

5 Miller H. Trauma and multiple sclerosis. Lancet 1964;1:848-50.

6 Millar J. Multiple sclerosis: a disease acquired in childhood. Springfield, Illinois: Charles C Thomas, 1971:65.

7 Poser C. Trauma and multiple sclerosis. An hypothesis. $J$ Neurol 1987;234:155-9.

8 McAlpine D, Lumsden CE, Acheson ED. Multiple sclerosis. A reappraisal. London: Churchill Livingstone, 1972.

9 Miller $\mathrm{H}$, Schapira K. Aetiological aspects of multiple sclerosis. BMJ 1959;1:707.

10 Shealy CN. Transcutaneous electrical stimulation for control of pain. Clin Neurosurg 1974;21:269-77.

11 Panse F. Electrical trauma. In Vinken PJ, Bruyn GW, eds. Handbook of clinical neurology Vol 23. Amsterdam: North Holland, 1975:686.

12 Hoesslin R von. Uber multiple sklerose: exogene aetiologie pathogenese, und verlauf. Munich: Lehmans, 1934.

13 Gonsette R, Andre-Balisaux G, Delmotte P. La permeabilite des vaisseaux cerebraux. Demyelinisation experimentale provoquee par des substances agissant sur la barriere hemato-encephalique. Acta Neurol Belg 1966;66:247-62.

14 Kelly R. Clinical aspects of multiple sclerosis. In: Koetsier JC, ed. Handbook of clinical neurology. Amsterdam Elsevier, 1985:64.

15 Ridley A, Schapira K. Influence of surgical procedures on the course of multiple sclerosis. Neurology 1961;11:81-92.

16 Sibley WA, Bamford CR, Clark K. Clinical viral infections and multiple sclerosis. Lancet 1985;1:1313-5.

17 Sibley WA. Risk factors in multiple sclerosis-implications for pathogenesis. In: Serlupi Crescenzi G, ed. A multidisciplinary approach to myelin diseases. New York: disciplinary approach to my
Plenum Press, 1988:227-32. 